\title{
Collection, storage and management of high-water marks data: praxis and recommendations
}

\author{
Olivier Piotte ${ }^{1, a}$, Céline Boura ${ }^{2}$, Anaïs Cazaubon ${ }^{3}$, Carine Chaléon ${ }^{4}$, Dominique Chambon ${ }^{5}$, Gwenaël Guillevic ${ }^{6}$, Fabien \\ Pasquet $^{7}$, Céline Perherin ${ }^{8}$ and Emmanuel Raimbault ${ }^{9}$ \\ ${ }^{1}$ French National Flood Forecasting Service (SCHAPI), 42 avenue Gaspard Coriolis 31057 Toulouse, Cedex 01, France \\ ${ }^{2}$ Cerema, Territorial Division for the Western Region (DTerOuest), rue René Viviani, BP 46223, 44262 Nantes Cedex 2, France \\ ${ }^{3}$ Cerema, Territorial Division for the Western Region (DTerOuest), 23 avenue de I'Amiral Chauvin, BP 20069, 49136 Les Ponts-de-Cé \\ Cedex, France \\ ${ }^{4}$ Middle Seine-Yonne-Loing Flood Forecasting Centre (SPC SMYL), 10 rue de Crillon, 75194 Paris Cedex 04, France \\ ${ }^{5}$ Garonne-Tarn-Lot Flood Forecasting Centre (SPC GTL), Cité administrative Bât. G, 1 rue de la cité administrative, CS 80002, 31074 \\ Toulouse Cedex 9 \\ ${ }^{6}$ Cerema, Centre for Prototype Study and Design (CECP), 23 avenue de l'Amiral Chauvin, BP 20069, 49136 Les Ponts-de-Cé Cedex, \\ France \\ ${ }^{7}$ Loire-Cher-Indre Flood Forecasting Centre (SPC LCI), 5 avenue Buffon, BP 6407, 45064 Orléans Cedex 2 \\ ${ }^{8}$ Cerema, Technical Division for Water and Waterways (DTecEMF), Technopôle Brest Iroise, 155 rue Pierre Bouguer, BP 5, 29280 \\ Plouzané Cedex \\ ${ }^{9}$ Lower Seine-Normandy Coastal Rivers Flood Forecasting Centre (SPC SACN), 1 rue Dufay, 76100 Rouen
}

\begin{abstract}
High-water marks data, in its most general definition, is a precious source of information for the many stakeholders involved in risk culture, inundation mapping, river, estuarine or coastal studies, etc. Although there have already been many initiatives to collect and exploit existing data, as well as collecting new marks after flood events, a lack of harmonization and coordination remains. The French flood forecasting services, together with Cerema, decided to provide technical and organizational solutions in order to set up a collaborative management approach of high-water marks data. On the one hand, a methodological handbook has been produced, giving recommendations for post-flood field investigations. It comes with a dedicated PDA tool and a PC desktop software. On the other hand, a national repository has been built, making it possible to gather the large range of informations usually needed. This repository is combined with a collaborative web platform, which aims to be a way of public access to the available information, a working tool for technical users, and a front door to contribute to the inventory. The last step of this approach is the setting of an organization blue-print including all the stakeholders directly or indirectly involved in high-water marks knowledge.
\end{abstract}

\section{Introduction}

Silent witnesses that human beings have left to keep the memory of historical events, flood marks are essential elements of knowledge for risk prevention. Often victims of the time, sometimes forgotten, mutilated, destroyed, they are a fragile heritage that is important to protect and preserve (Gazelle, Maronna, 2009 [1]). Their conservation and development go through a necessary inventory. Flood marks have many interests for multiple recipients:

- the general public (visual objects, easily recognizable in public places, vector of risk culture and effective means of information and comparison during a new flood);
- elected representatives (to communicate on flood risk and fulfil their legal obligations);

- stakeholders involved in flood-risk prevention and flood forecasting among the State services or territorial institutions (indispensable historical data for flood mapping, hydrodynamic model calibration etc. - for exemple the many studies performed on the Loire river $^{1}$ );

- more broadly, the stakeholders involved in river or coastal management and planning (essential knowledge elements when performing morphological, hazard or impact studies, hydraulic works dimensioning etc.).

${ }^{1}$ http://www.centre.developpement-durable.gouv.fr/mise-a-jour-de-laconnaissance-des-plus-hautes-a883.html

\footnotetext{
a Corresponding author: olivier.piotte@developpement-durable.gouv.fr
} 
Complementing this knowledge of past floods, many other data continue to be collected after each new event. This mainly concerns ephemeral flood marks that subsist once water has receded and which provide information on the extension of the floods and the reached levels at different points.

To meet these diverse needs, many stakeholders in France have already carried out initiatives to collect and exploit existing data, as well as collecting new marks after flood events, but without a full harmonization and coordination: several inventories may coexist for the same territory, post-flood field investigations can sometimes be performed twice or using unharmonized methods, collected data is seldom widely shared.

The reflections initiated among the flood forecasting and hydrometry network ${ }^{2}$ resulted in two joint actions:

- the collegiate production of a methodological handbook for post-flood field investigation, accompanied with a software application;

- the development of a national repository and a collaborative web platform, dedicated to flood marks capitalization.

\section{Flood Marks}

The term "flood marks" brings together a wide variety of objects of all kinds, all shapes and relating to all types of floods.

\subsection{Historical and physical marks}

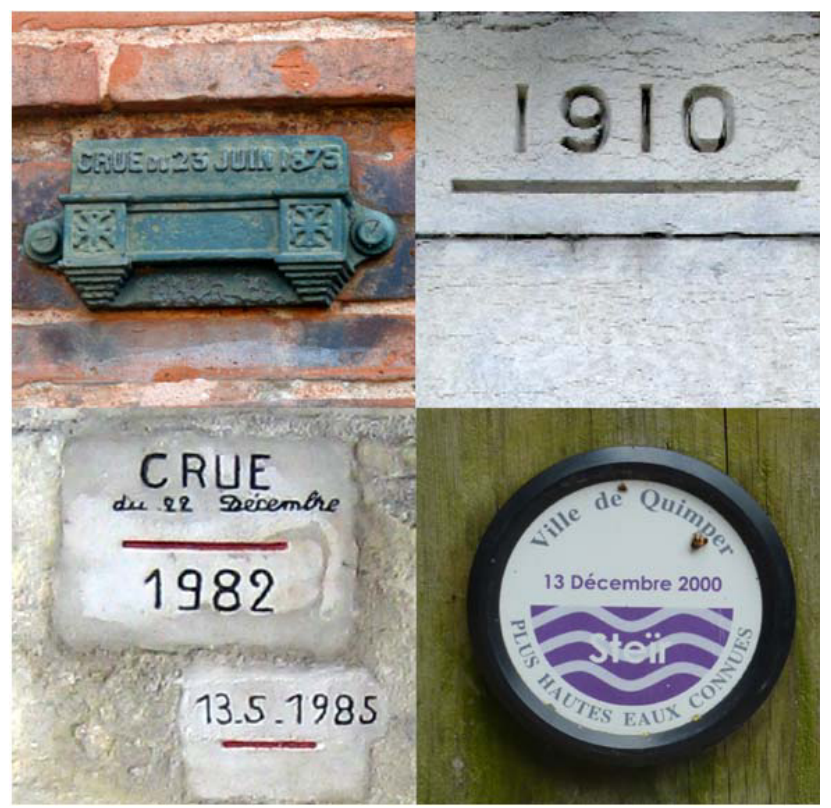

Figure 1. Examples of physical and historical high-water marks (SCHAPI, DRIEE Île-de-France, Cerema).

\footnotetext{
${ }^{2}$ Gathering the French national flood forecasting service and local flood forecasting centres
}

These are physical objects which materialize the levels reached during a flood event. They usually contain two types of information: an indication of the water level and a reference to the flood event.

They are mostly found in two forms. The - mostly historical - engraved, painted marks or sealed plates, which are relatively sustainable marks, help to preserve the risk culture if they are visible and in good condition, and have some heritage value. And the normalised plates, placed more recently in application of the preventive information policy ${ }^{3}$, which can either be historical marks that have been turned into normalised plates (directly or after interpolation between surrounding marks) or related to more recent events.

\subsection{Temporary flood marks}

It refers to the temporary traces left by a flood or marine submersion. Temporary flood marks can take the shape of a deposit - on the ground, on a wall, hung on a fence or a branch - of different kinds of matter (solid objects, sand, silt, plant debris, plastic waste), traces of moisture etc. These marks have a limited durability and can sometimes involve a high degree of uncertainty.

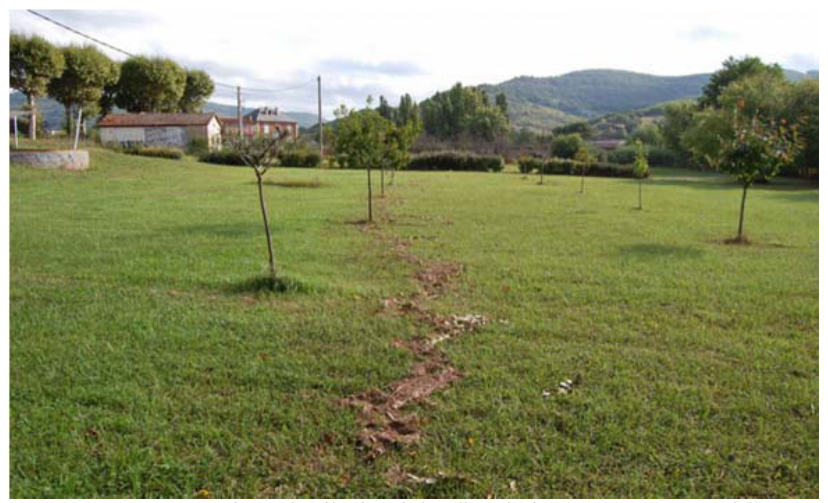

Figure 2. Deposit at the limit of the flooded area (DREAL MidiPyrénées/Geosphair, Dourdou river flood, 2014).

Among the temporary flood marks, the high-water mark $\left(\mathrm{PHE}^{4}\right)$ deserves to be distinguished because it provides information on the highest level reached by the water during the considered flood event. These are the neat traces left on a fixed support.

They are to be found on public or private buildings, homes, bridges, boundary walls, immoveable vegetation, etc. They are characterized by their relative height in relation to a reference that can be the ground, the floor of a building, the threshold of a door. Some of these flood marks may subsequently be turned into physical marks.

\footnotetext{
${ }^{3}$ March 16, 2006 act.

${ }^{4}$ PHE: Plus hautes eaux
} 


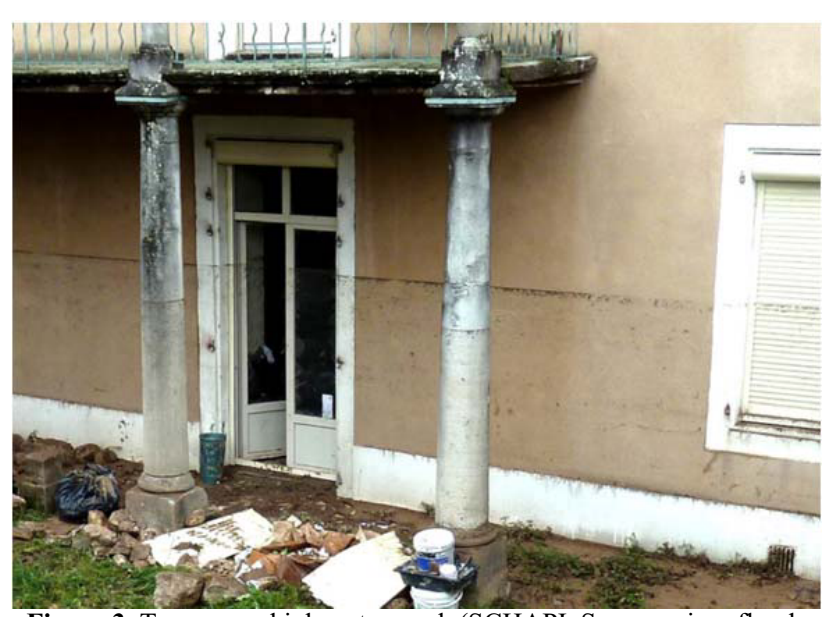

Figure 3. Temporary high water mark (SCHAPI, Sorgues river flood, 2014).

\subsection{Other information left by floods}

Without replacing the proper investigations that require a comprehensive analysis of the morphodynamic behavior of a river (or coastal area) during a flood, postflood field investigations enable to collect some information about flow dynamics and the disorders they have caused: origin of the flood (upstream / downstream flows within the flood plain, floods generated by lateral inflows, overflowing or breakage of dams or dikes), presence of obstacles to the flow, silt or sand deposit in low speed flow areas, high speeds and preferential flow areas in floodplain (plants uprooting, damages caused to pavement, fences, buildings), digging of drainage channels in the floodplain, erosions or collapses of river banks etc.

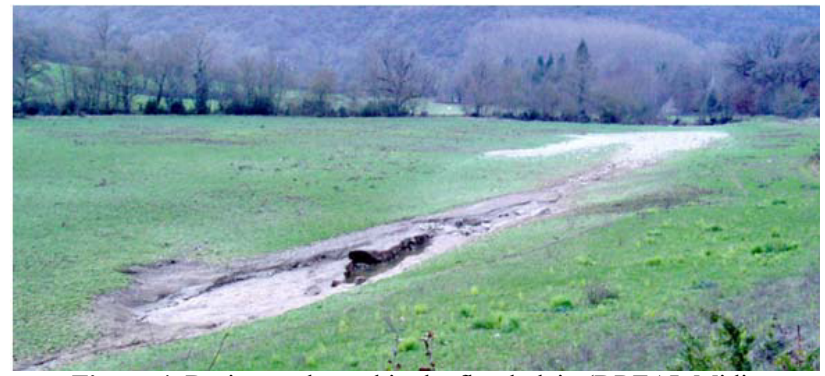

Figure 4. Drainage channel in the flood plain (DREAL MidiPyrénées/Klaus Maronna).

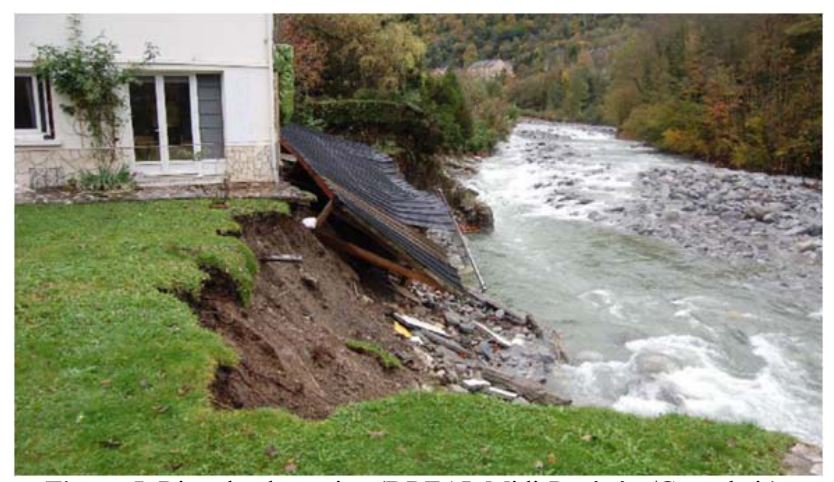

Figure 5. River bank erosion (DREAL Midi-Pyrénées/Geosphair).

\subsection{Evidence of flooding}

Among all the possibly collected data, should also be mentioned:

- visual representations of events (photographs, postcards or iconography), which are more valuable if they depict the maximum level reached during the flood;

- written or oral reports, with related reliability issues.

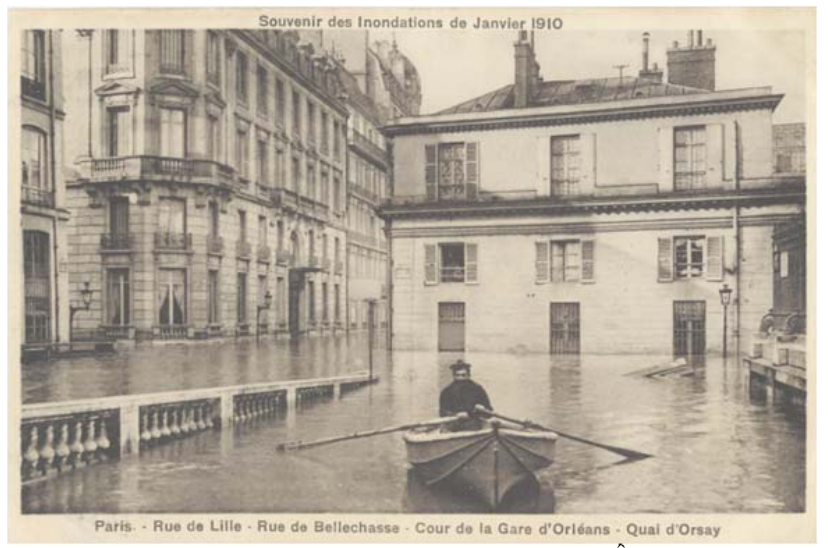

Figure 6. Postcard of the Paris 1910 flood (DRIEE Île-de-France).

To sum up, the common interest of all these information is the provision of a visual or technical testimony of the water level reached during a past flooding, at a given place.

\section{Field investigation tools}

\subsection{Methodological handbook}

For future events, a specific methodology is purposed to describe the flood as accurately as possible and to depict precisely what happened (Cerema, 2016 [2]). The methodological recommendations of this handbook have been elaborated after a survey about field experiences ${ }^{5}$ and after analysing previous French handbooks (MATE, 2001 [5] ; Gazelle and Maronna, 2005 [6]).

A similar project has been conducted simultaneously in the USA, with a detailed guide recently published (USGS, 2016 [7]).

\subsubsection{What to collect?}

Among the different flood marks, the high-water marks are the ones to collect as a priority. Indeed, thanks to them, it is possible not only to identify a flooded area but also to know the highest water level reached during this event. These data are crucial for the capitalisation and the comparison with precedent events. The highwater marks survey can't be exhaustive and the places

${ }^{5}$ Several reports of former floods have also been exploited, for example on the Dordogne basin (Epidor, 2008 [3]) or on the Mérantaise river (DDE 91, 2007 [4]) 
where to perform measurements must be chosen in order to well-depict the flooded area. The other water marks (only indicating the passage of water) must be collected in sites where high-water marks aren't visible to refine the knowledge of the flooded area. The measurements mesh must cover the whole flooded area. The mesh must be denser in areas of strong variations in the water level, generally in the presence of flow obstacles.

\subsubsection{How to collect?}

The survey must be realised as soon as possible after the water has receded (not necessarily completely). The measurements must systematically be performed where previous high-water marks have been noticed and on particular points along rivers, such as gauging stations, hydraulic works, bridges or other structures (including discharge structures), confluences, most exposed and visible public building, etc.

Each high-water mark must be drawn with a marker, chalk or paint on its support, in order to durably keep track of the mark until the end of the survey.

It is recommended to take at least two pictures of the mark, to help its future tracking : one general view of the site to visualise the mark support and its close surroundings, and one close shot of the mark itself. An information sheet must be filled to describe the mark (type of mark, support) and its surroundings. It is necessary to collect the precise location of the mark, by GPS/DGPS and/or by reporting it on a map. The mark must preferably be levelled posteriorly, during specific field investigations made by surveyors, or calculated from former well-known level on the same site.

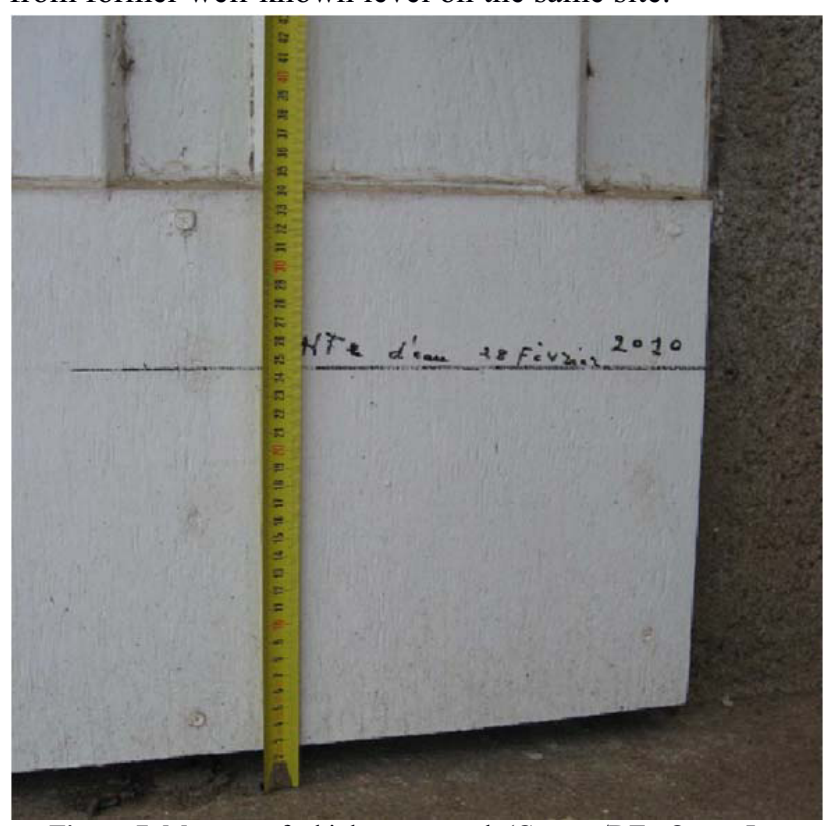

Figure 7. Measure of a high-water mark (Cerema/DTerOuest, La Tranche-sur-Mer, 2010)
To make data collection easier, several tools enable the databasing of information during field studies.

One of them, named CRISI (for post-flood investigation and data collection) was developed by the CECP (Centre for Prototype Study and Design) in Angers. It includes an application installed on a PDA terminal "CRISI PDA" for field studies and a PC desktop version "CRISI_BUREAU" linked to the field tool. It will be made available to users and State services involved in flood and risk prevention, in connection with national guidelines.

\subsection{1 "CRISI_PDA" application}

This digital tool, adapted for post-flood investigation, improves the quality of data collection and the optimisation of the time dedicated for site visits. Its utilisation is also quick and easy.

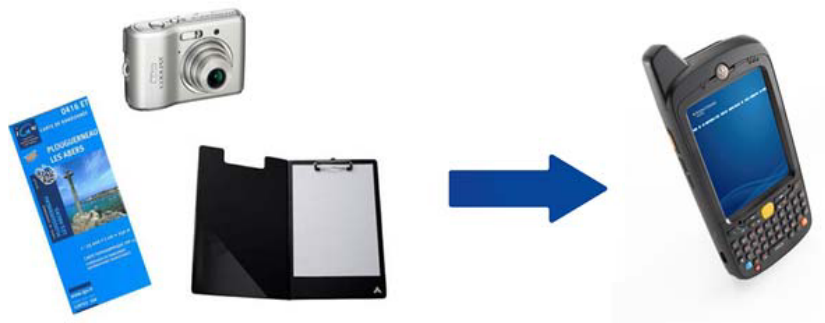

Figure 8. CRISI application tool (Cerema/DTerOuest, 2016).

Three collating worksheets, derived from national guidelines, were created and included in the PDA application for the field-study part.

A visit or survey worksheet gives details of the operator, the investigation site and information about flood events and is linked to topographic studies.

A topographic observation worksheet describes water mark data (water or temporary silt markings, vegetation. etc.) and in particular high-water marks to provide information about flood features.

A report worksheet gives details of flood chronology but also the extent, flow direction and speed of the event. This worksheet is the result of report collected from residents, elected representatives etc.
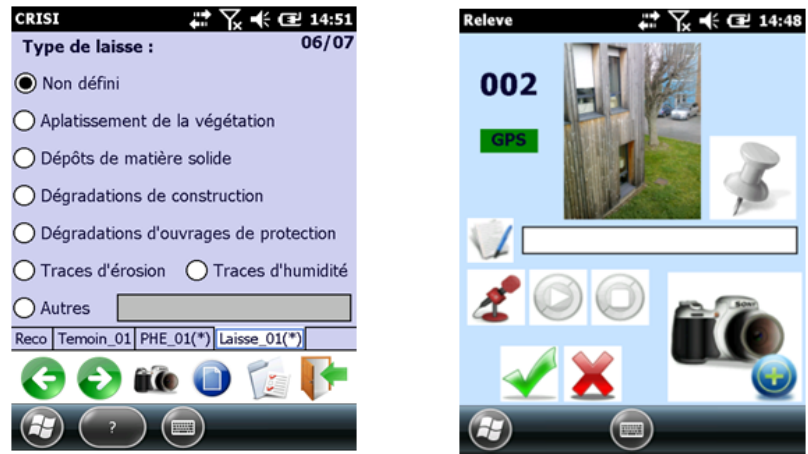

Figure 9. Worksheet example (water mark description) and additional tools (Cerema/DTerOuest, 2016). 
GPS, an electronic compass and a camera are included in the field tool in order to complete these worksheets with an automatic recording of itineraries, geo-referenced pictures (with GPS position and bearings) and audio comments.

\subsection{2 "CRISI_BUREAU" PC desktop software}

After field investigations, the desktop software tool is used for ordering and approving the collected information but also databasing it.

Firstly, the "CRISI_BUREAU" software allows the field data to be imported and the itinerary and GPS waypoints (linked with pictures and audio comments) to be viewed. The visit worksheets can be arranged to organize data into collection files and also to change precompleted fields and give more information about flood events, altitude, levelling measurements or report details.

Secondly, these results can be exported depending on the performed data analysis. In fact an automatic report with the different worksheets can be created in a LibreOffice format, worksheets field information can be extracted in .csv format and all the information about geographical objects, tables and pictures, compatible with GIS structure, can be exported.

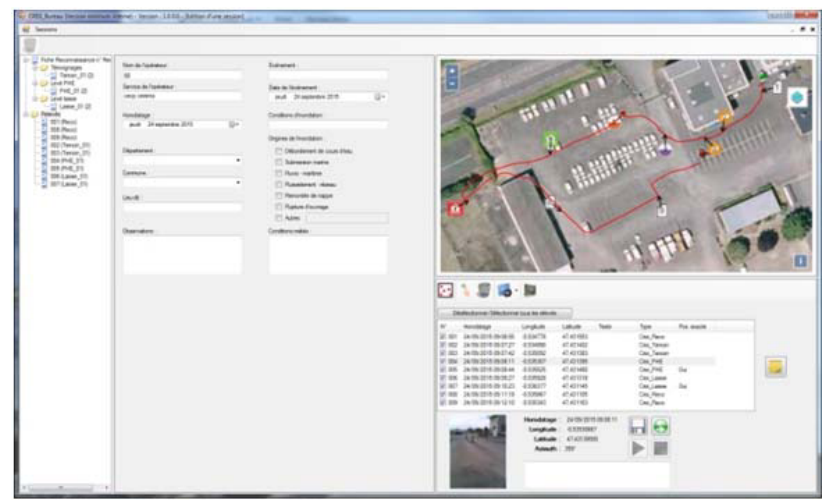

Figure 10. PC desktop software (Cerema/DTerOuest, 2016).

These data can be databased and exploited in GIS creating a local database and then directly supplying the national repository with the files exported in .csv format. Thus, data availability for all stakeholders is ensured.

\section{National Repository}

As heirs of past work, French governmental services and river basin districts manage numerous and variously structured databases about high-water marks, designed for different uses. These databases concern the main great watersheds (Seine ${ }^{6}$, Loire ${ }^{7}$, Garonne (Maronna, 2001 [8]), Saône or Doubs ${ }^{8}$ rivers watersheds) as well as smaller

\footnotetext{
${ }^{6}$ http://www.reperesdecrues-seine.fr/

7 http://www.centre.developpement-durable.gouv.fr/les-reperes-de-crues-r501.html ${ }^{8}$ http://www.eptb-saone-doubs.fr/Reperes-de-crue
}

ones $\left(\mathrm{Aa}^{9}{ }\right.$, Charente $^{10}$ or Sèvre nantaise ${ }^{11}$ rivers for exemple). In order to unify, improve and spread good practices, a unique national database has been built.

\subsection{Repository structure}

\subsubsection{Four main notions}

Since several marks may stand at the same location, in order to correctly describe them, there is a need to differentiate:

- Site information: geographical information of location and its environment;

- Mark information: describing of a mark itself, especially altitude and related flood event.

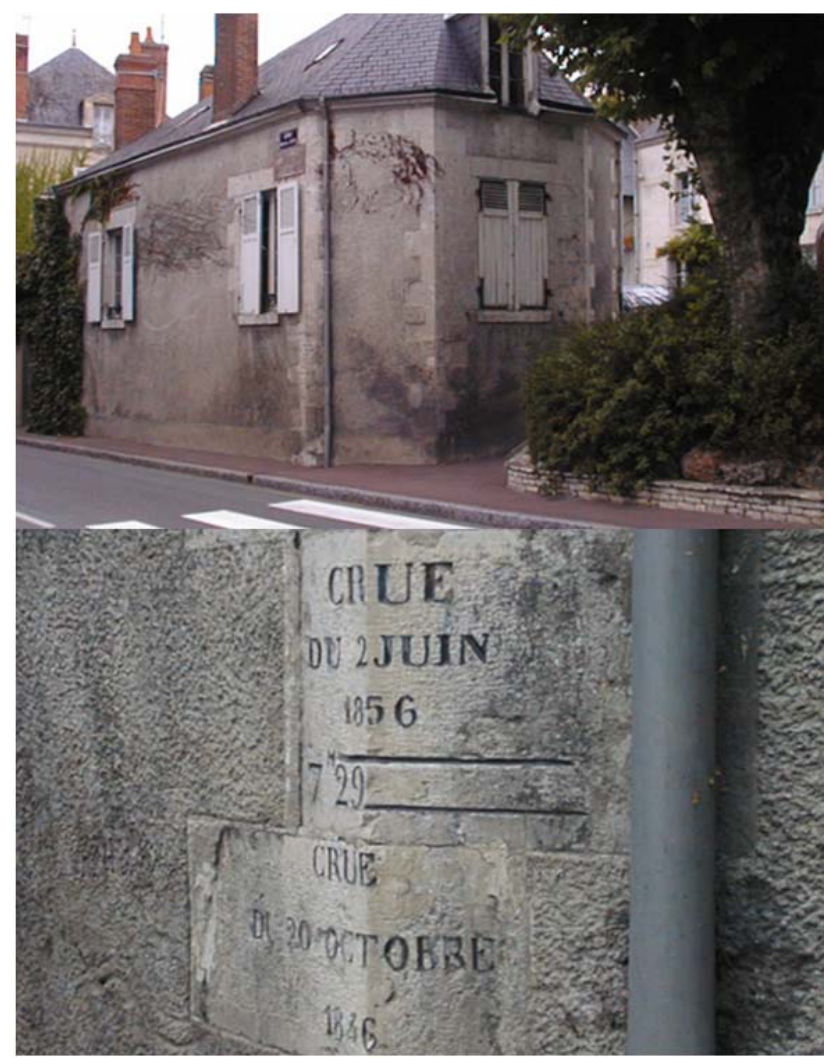

Figure 11. One site, with several high-water marks (DREAL CentreVal de Loire, Gien).

From this distinction, two other essential characteristics naturally follow:

- Hydrography (river or sea) in the surroundings, originating floods (site-related information);

- Flood event at the origin of the mark (markrelated information).

\footnotetext{
9 http://phototheque-crues.smageaa.fr/index.html

${ }^{10} \mathrm{http}: / / \mathrm{www}$. fleuve-charente.net/actualites/localisation-des-reperes-de-crues.html

${ }^{11} \mathrm{http}: / /$ www.sevre-nantaise.com/observatoire/page-reperes-de-crue
} 
Finally, the fundamental repository structure consists in these four main items, theoretically sufficient to well describe registered high-water marks.

\subsubsection{Detailed characteristics}

Beyond this first approach, these main characteristics need to be specified for a technical use of the information (through hydraulic studies for example). Detailed information are:

- Description of the flood event at the origin of the mark: which process (overflowing from river bed, uprising alluvial groundwater, flood from the sea in coastal areas...)? Which event return period? Does the mark correspond to highest historical water level?...

- Accurate description of the location where marks stand: is the support damaged? Who is the owner of the building? Is it easy to access?...

- Accurate mark description: which kind of mark is it? Is it temporary? Does the mark need to be restored? Is it visible from the street?

- Data source description: do we know the information from a former inventory? Which is the source document? How to conserve the first description, if it needs to be corrected?

- Data expertise: does the altitude above sea level of the mark enable to finally reconstitute a plausible river profile? How precise is the altitude?

This last notion about uncertainty, is, with the altitude of the mark, the most elaborated information that can be extracted from the repository. Quality and utility of the mark information are depending on this notion of precision, for either a technical use (how to calibrate a hydraulic model at this point?) or communication campaigns on risk prevention (may the mark be used to illustrate historical flood levels towards the residents?). Consequently, this information is the most difficult to obtain. It needs accurate studies about the event, the other marks in the surrounding area and the local hydraulic phenomena.

\subsubsection{Simplified repository structure and multiple levelling question}

Picture below represents a simplified description of the repository, built around the four main notions, previously presented.

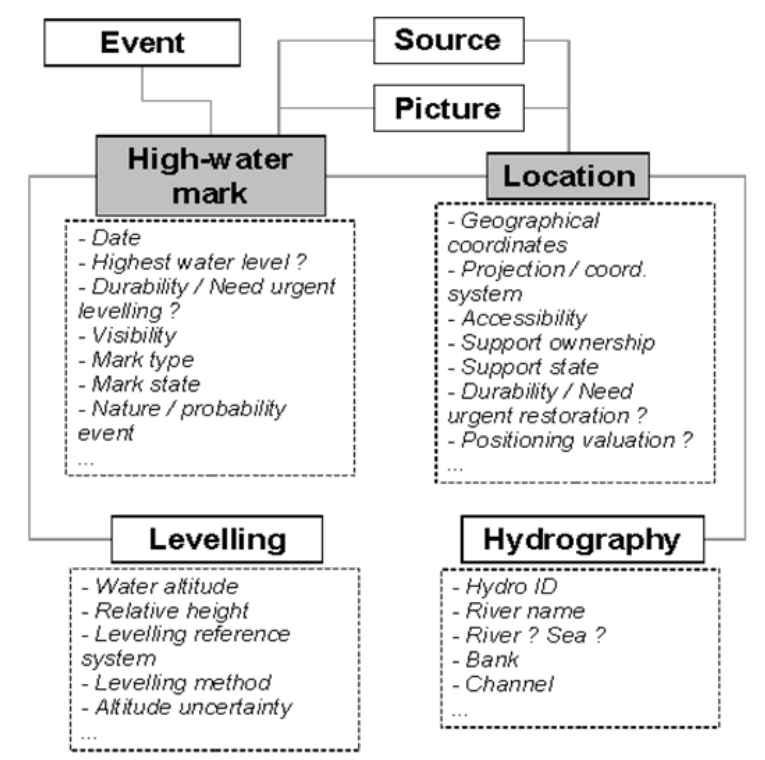

Figure 12. Repository simplified structure.

Although a single height value may seem enough for a mark, keeping successive historical values may be necessary. A lot of ancient registers use former levelling reference systems. The comparison of the converted former value with the new altitude value (in the current reference system) of a single mark can indicate measurement errors or a shift of the mark. In case of a disappeared mark, keeping a former value enables a potential future conversion correction. Consequently, levelling is an important notion, which must be clearly identified in a proper table of the repository.

Moreover, pictures and photographs need to be databased, as significant description items and as the main component for communication about the high-water marks through the web platform. Nevertheless, these pictures and photographs consist in numerous high size files conditioning the necessary repository server space.

\subsection{Former data integration}

The second step after the repository building is the integration of former inventories, starting with the ones on the Seine, Loire and Garonne river catchments, counting more than 10000 databased marks.

To be integrated, former data first need to be adapted to the new repository structure, respecting all the original informations. Moreover, this integration process is often an opportunity to clean up data. The main processes concern the next items:

- for some inventories, geographical setting and mark description must be distinguished;

- description values are not always the same in former and new databases: fields relations have to be set. When accurate relations can not to be found, data are stored in multiple comment fields. The purpose is to lose as less information as possible; 
- numerical identification of former records must also be retained, in order to be able to study again native data in case of future problems;

- for an attractive display of the data sheet, a short description must be written, generally needing manual tasks;

- in the aim of public broadcasting of these informations, image rights must be preserved: people faces and vehicle number plates, which appear on photographs, should be erased or blurred;

- more generally, correct links between photographs and mark informations have to be verified and ensured.

These preliminary operations are often long and can't always be automated. But they are necessary to enable a correct start for the national repository, with a good integration of existing inventories and a good visibility of the web platform.

\section{A collaborative web platform}

The repository is combined with a collaborative web platform, which is the most visible part of the whole project:

www.reperesdecrues.developpement-durable.gouv.fr (launch scheduled in September 2016).

It aims to be at the same time a way of public access to the available information about high-water marks, a working tool for technical users of the data, and a front door to contribute to the inventory.

\subsection{User profiles}

In order to allow open contribution from any concerned stakeholder, ranging from the citizen to the expert service, and to foster a collaborative management approach, four user profiles have been defined (apart from the administrators of the platform):

User: meant for occasional and unauthenticated internet users, for consultation of basic and descriptive data about high-water marks;

Contributor: meant for flood risk aware internet users, willing to contribute to the inventory; the information to be entered is limited to the minimum in order to encourage open contribution and to reserve the most technical information to the specialists; contributions from a contributor profile come with an "unverified" status;

Expert contributor: meant for public or private professional stakeholders, able to complete most of the awaited information and to reliably determine some technical data such as the altitude of the mark, the reference flood event, the source of the data etc. ;
Data manager: geographically distributed between several regional (or above-regional) services with a watershed competence; meant for the referent service of each territory, in charge of verifying and publishing contributions, as well as evaluating the data and identifying expert contributors.

\subsection{Information browsing}

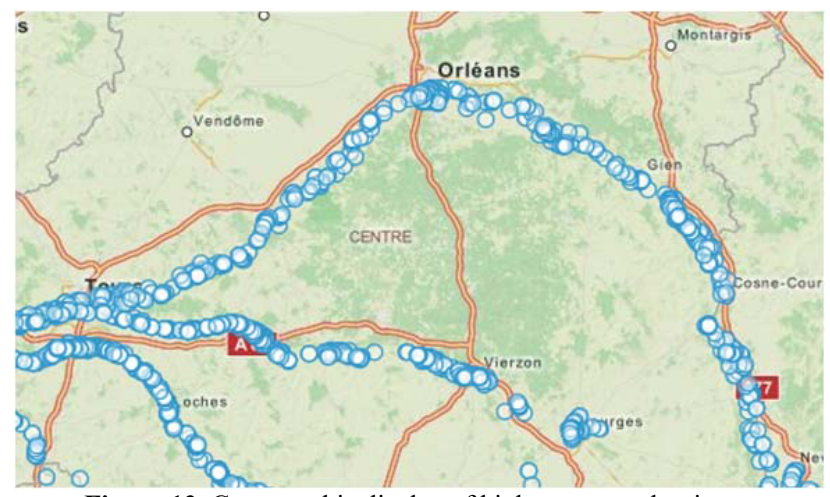

Figure 13. Cartographic display of high-water marks sites.

The internet platform allows any internet user to access to most of the information in the repository. Only a few advanced data fields are reserved to registered users with upper profiles. It has the usual range of features for this kind of application: display under cartographic shape or as a list, search functions and multi-criteria filters, newsfeed etc.
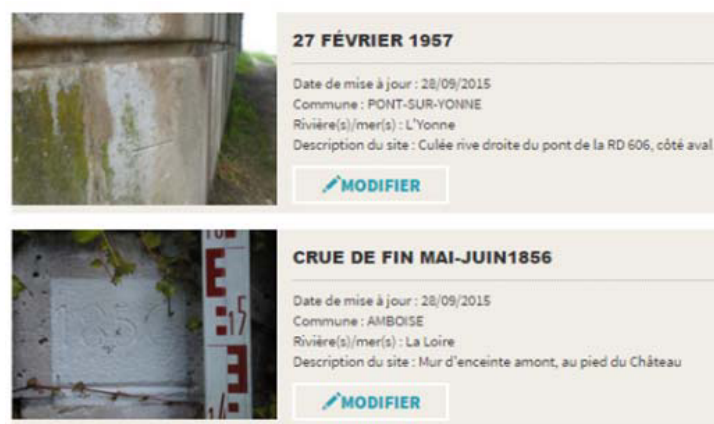

CRUE DE FIN MAI-JUIN1856

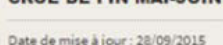

Commune : AMBolise Rivitrela/mer(s) : La Loire pescription du site : Mur denceinte amont, au pied du Chabteas IMODIFIER

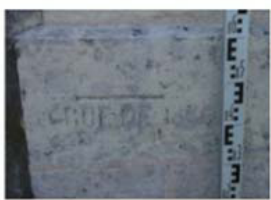

CRUE DE SEPTEMBRE-OCTOBRE 1866

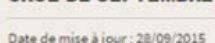

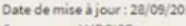
Commune : AMBOIS: Description du site : Aun'45 du quai des violettes 'MODIFIER

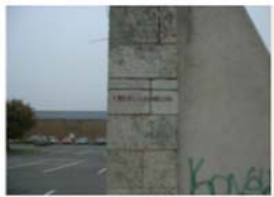

CRUE DE FIN MAI-JUIN1856

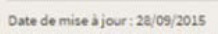

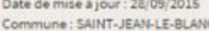
Rivitere(s)/meris) : La Loire Sescription du site : Jardinerie Truffaut - sur un ancien portail 'MODIFIER

Figure 14. Display as a list on the web platform. 


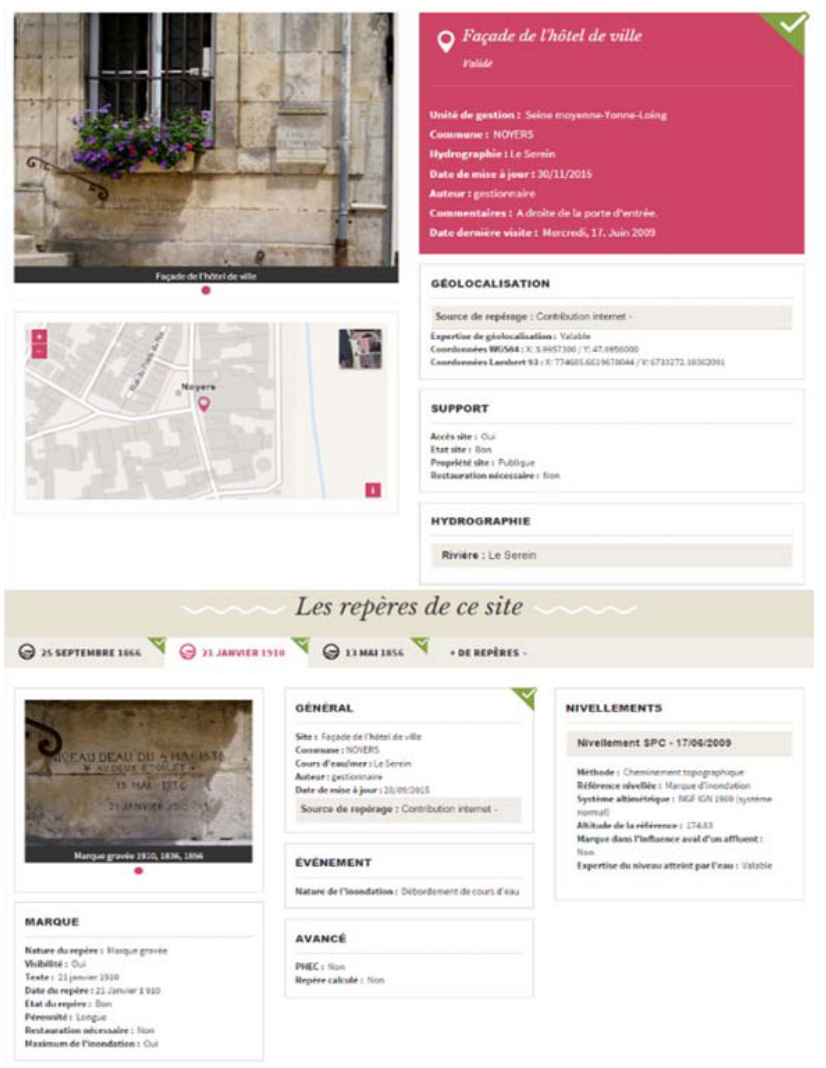

Figure 15. Site and marks datasheet.

Beyond the direct display, the platform also enables to perform on-demand list exports and data-sheet prints. Moreover, in an interoperability purpose, the access to the data is possible through web services, allowing for example to retrieve and display it in a GIS client or any other dedicated application.

\subsection{Contributory aspect}

Apart from historical or temporary high-water marks investigation campaigns, organised by administration services or local authorities, open contributions must be also taken into account, as it can become a prolific source of new information.

Inspired by the local website dedicated to high-water marks on the Seine river basin ${ }^{12}$ (which already offered open contribution features since its opening in 2010), the national platform allows open contribution from any internet user with at least a contributor account (without restriction at creation). A contribution only needs a few information to be accepted: geographic position on the cartographic display, brief description of the location, date of the flood event, indication of the high-water level reached (through a striking photo or a precise account). Of course, it can be much more detailed at the outset, if additional information is known.

\footnotetext{
12 www.reperesdecrues-seine.fr
}

Portable devices with an internet connection also enable to easily submit contributions from the field, thanks to the use of embedded features such as satellite positioning and camera. Even if it could also be used in genuine field investigation campaigns, this specific function is definitely turned towards the general public, whereas CRISI tool (see 3.2) is dedicated to professional users.

\subsection{Data and user management}

In order to guarantee the best possible quality for the data in the repository, the platform includes several functions dedicated to data managing.

Indeed, the integration of a contribution first requires a checking task, especially for an open contribution, coming from a local resident after a flood event for example. Secondly, after being checked, the contribution can be completed by an expert service - with an "expert contributor" or "data manager" account - able to add advanced information such as the high-water mark altitude. The same process can also occur when integrating a pre-existing inventory: the national repository, built to fit enlarged needs, would probably allow to add information that weren't supported in the original inventory.

More generally, because of their nature, age or the relevance of their description, high-water marks include potentially significant uncertainties. Therefore, each entry within the repository must be supported by a quality indicator, enabling users to sort informations and identify which ones to use. Thus, three validation levels have been defined:

Published: the publication is generally decided after a first level review performed by the data manager in order to ensure that the contribution is honest, or can be bound to the verifying step. It has the effect of making data visible on the platform for any internet user;

Verified: it testifies that an expert service (data manager or expert contributor) has performed a qualitative control of the data, ensuring its general relevancy (correct filling of the requested information, presence confirmed by an on-field visit, known flood event, location within the flood area etc.);

Expertised: it requires from the data manager an indepth study of the high-water mark, which usually consists of a comparison with other high-water marks for the same event along the river. This ultimate level can be reached several months after the contribution act or the verifying step. It assesses the quality of the threedimensional position of the mark and its relevancy to represent the water level of the considered event, which can be:

- $\quad$ valid $=$ the mark offers a reliable representation of the considered flood event with reasonable uncertainties, and its position can be used with confidence; 
- $\quad$ inaccurate or doubtful $=$ the position of the mark is approximate or unreliable because of its nature, the poor accuracy of its measurement, a local singularity etc. It should be used with caution, and not for any purpose;

- $\quad$ unlikely = the mark data suffers from significant incoherence. The mark may have been moved or misplaced, the related flood event may be wrong. Its position data should not be used.

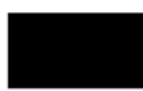

Unverified

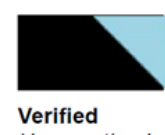

Verified
Unexpertised Unexpertised

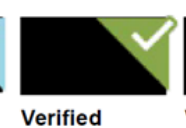

Verified Valid

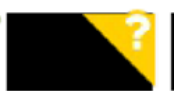

Verified Inaccurate or Unlikely doubtful Expertise: $\quad$ Expertise :

Figure 16. Validation icons.

The platform also features a back-office enabling data managers to perform data management operations such as advanced search, contribution monitoring, batch processing, versioning, user management etc.

\section{Integrated and collaborative management}

The national repository and its related web platform are designed for the general public and specialists as well to input or consult items from short term to long run use. They make it easier for private citizens and flood experts to use data and for stakeholders to communicate, as it has been done for hydrometric data decades ago. It spares time for collecting and completing data instead of shaping it. It is also very useful to coordinate restorations, compare or validate data.

\subsection{Stakeholders}

\subsubsection{Institutional stakeholders}

State services deal with floods since centuries. Flood forecasting services and navigation services have been involved in collecting reliable flood information for numerous French rivers.

Nowadays, this involves every administrative level dealing with the subject, from the national level with the national flood forecasting service (SCHAPI ${ }^{13}$ ), flood forecasting and hydrometry centres. More locally, at the level of the French "departments", other services ${ }^{14}$ participate in preventing, handling the crisis and analysing it afterwards. These services can rely on the skills of Cerema which leads scientific research and

\footnotetext{
${ }^{13}$ SCHAPI (Service Central d'Hydrométéorologie et d'Appui à la Prévision des Inondation) coordinates flood forecasting and hydrometry activities

${ }^{14}$ The DDTs (Direction Départementale des Territoires) and SIDPCs (Service Interministériel de Défense et de Protection Civile), under the authority of the local prefect
}

practical projects for the French State administration and local authorities.

Apart from French State services, local authorities are also particularly concerned with rivers and flood-risk management. Municipalities, as the most local level, and river basin territorial public institutions (EPTB ${ }^{15}$ ), represent two significant sources of data with a useful local knowledge. EPTB are especially in charge of coordinating, animating and guiding the involved stakeholders within the watershed territory and may also carry action plans $\left(\mathrm{PAPI}^{16}\right)$, which are powerful floodrisk management tools.

State services and local authorities share numerous issues dealing with floods, making the use of common tools recommended.

\subsubsection{Civil society stakeholders}

Engineering companies and surveyors do participate to the knowledge improvement on floods. Contributing to the national repository should become a natural part of the specifications they have to comply with while working for the State services or local authorities.

Private citizens, as first witnesses willing to share their experience and final recipients of flood-risk prevention actions, are aimed to highly contribute to the repository wealth.

\subsection{The organisation for field investigations}

\subsubsection{General principles}

The flood occurrence, sometimes sudden, rarely allows time to well-organise field investigations. To ensure reactivity, coordination between stakeholders and thus efficiency and reliability of future field investigations, a preparation is essential. This preparation may often take the form of a collection protocol. Recommendations have been issued to elaborate these protocols (Cerema, 2016 [2]).

A protocol explains the key stages of the field investigations organisation and how to implement it within a predetermined area related to similar flooding conditions. This guidebook defines the main stages of the investigation: prior organisation, operation triggering, onfield organisation, technical aspects, devices and data capitalisation.

Defining the field investigation organisation requires a prior networking of all potential partners (State services, public authorities...). This networking is particularly useful to define what type of collecting is favoured (outsourcing or not); who collects if there is no

\footnotetext{
${ }^{15}$ EPTB (Établissement Public Territorial de Bassin), river basin territorial public institution

${ }^{16}$ PAPI (Plan d'Action de Prévention contre les Inondations), action plans for flood-risk prevention, aiming to promote an integrated flood-risk management at the watershed scale
} 
outsourcing; how the collecting starts; who is in charge of the protocol implementation; how this operation is articulated with other ones in a close area.

Tools are proposed to develop the protocol in a shared mode, for the preparation and organisation stage (financial and human resources, equipment and maps) or the fields investigations which necessitate specific tools (pre-filled sheets).

Such attempts prevent data redundancy and optimise the often limited services means to cover in the best possible way all the flooded areas.

\subsubsection{Simplified measurements protocol of high- water level on the rivers of the city of Bourges}

Yèvre, Auron and Moulon rivers flow through the city of Bourges and can be the cause of major floods. They also identify the area as a significant flood risk territory, at the Loire basin scale (within the meaning of the European floods directive 2007/60/EC). In order to optimize measurement interventions in the field, the Loire-Cher-Indre flood forecasting centre has built together with the technical services of the city of Bourges a simplified measurements protocol. It deals with:

- joint preparation of a measurement points network: first, proper sites identification for water altitude measuring and then, photography and levelling of a surveyor's rod on these sites, that form virtual water level gauges;

- during water uprising, warning and request of the city technical services by the Loire-CherIndre flood forecasting centre;

- during the highest water level period, ideally included in usual round of inspection, city technical services take simple photographs on the measurements sites, using the same point of view as preparation photographs;

- post-flood comparison of both kinds of photographs, in order to determine the water altitude at each measurement site.

This protocol has been put into practice only once, during a very limited rise of the water level: no crippling problems have been identified, but some questions remained about the turnaround time and about the geographical position of measurement sites. Nevertheless, this kind of protocol is expected to be implemented on other main vulnerability areas within the Loire watershed.

If this kind of protocol enables to optimize services organisations during the event, city technical services are also interested in the results of the exploitation of the measures, more particularly by the flood extension maps made and shared by the Loire-Cher-Indre flood forecasting centre. The "win-win" principle of this protocol ensures its good application and its durability.

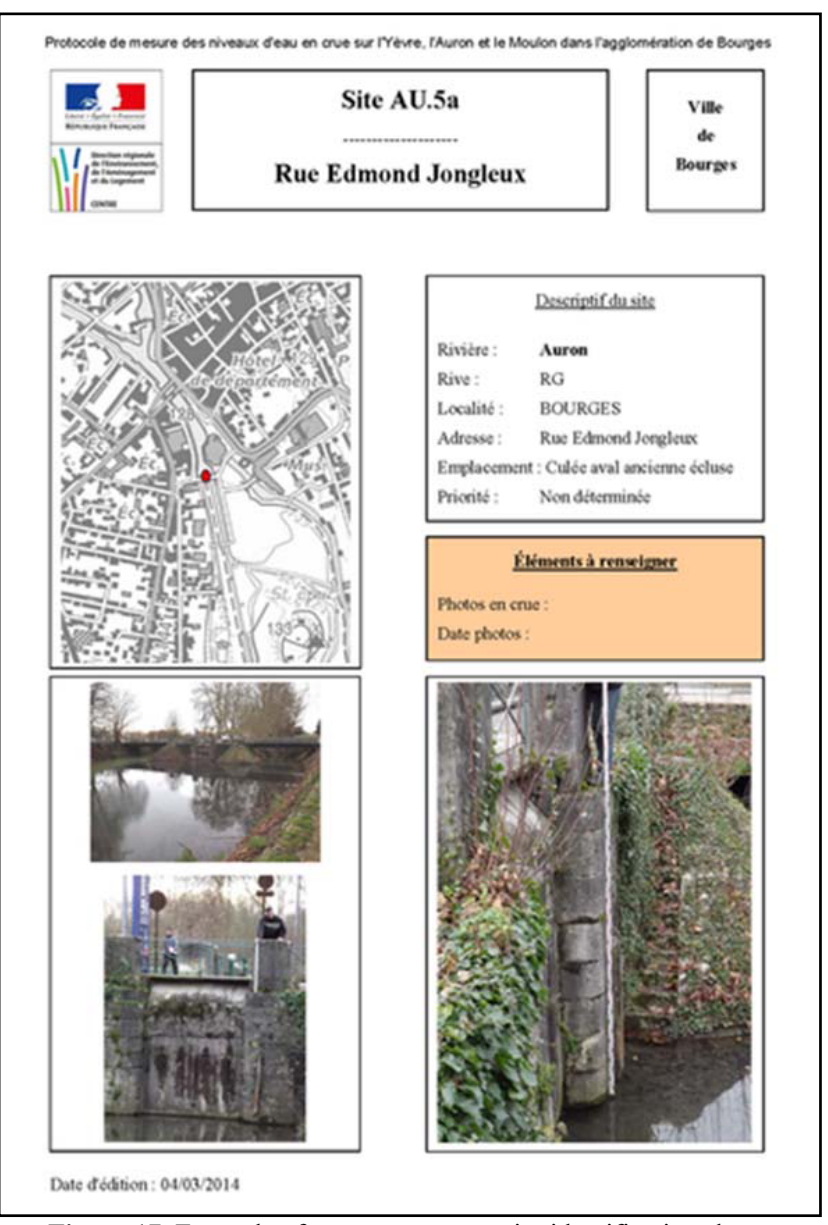

Figure 17. Example of a measurement point identification sheet.

\subsection{Management of the web platform}

As a shared tool designed for a collaborative management approach, the web platform allows each stakeholder to find its place.

Private citizens would mainly be contributors or simple users. For example, waterside inhabitants, teachers, students are expected to be able to share their local knowledge or experience this way.

Municipalities or other public services, depending on their implication and skills with flood-related issues, would be considered either as private citizens (simple users or contributors) or as expert contributors.

Public services specialized on floods, such as RDI mission $^{17}$, services dealing with risk-prevention policy, river basin districts etc., would mainly be expert contributors. Information they gather may come from projects or studies (flood prevention plans, protection works etc.) or specific post-flood field investigation campaigns (see 3.1). These expert contributors are also expected to complete the information shared by contributors.

\footnotetext{
${ }^{17} \mathrm{RDI}$ (Référent départemental inondation): within a DDT (see 6.1.3), local mission in charge of flood crisis preparation, crisis management, post-flood feedbacks, in relation with flood forecasting centres and civil security services
} 
Flood forecasting centres (or eventually river basin districts willing to assume this function) would be the data managers on their hydrographic area, without overlapping between territories. These services would be in charge of the validation process of the contributions (including the possibility to auto-publish unverified data which is a way to promote open contributions), data completion and expertise, contributors' management and the preparation of the data for batch imports.

An upper level of management, not linked to a territory, is achieved by a group of flood administrators constituted by members of the national flood forecasting service, local flood forecasting centres and Cerema. Their tasks include newsfeed and online help updates, modifications of nomenclatures and forms, historical flood event referencing, batch imports and versioning related operations.

\subsection{Interactions with other sources of information about floods}

The high-water marks repository completes other related information sources. The main ones are detailed hereafter.

BDHI $^{18}$ (www.bdhi.fr) is an institutional database that describes outstanding submersions in France whatever their origin. It relies on bibliography gathered and summed up by research institutes. It is to be completed by new documents or new observed phenomena. BDHI offers explanations and a general vision of the biggest floods while our platform brings local testimonies and water level data. Both should be related in the forthcoming years, particularly through the flood events present in both databases.

Géorisques (www.georisques.gouv.fr) is an institutional cartographic platform designed for each citizen or specialist who wants to be summed up the natural and technological risks that can occur at a given location. The user can have access to specific planning and risk-prevention documents dealing with those risks, flood maps etc. The addition of high-water marks data is planned. It will bring a complementary local knowledge.

Vigicrues (www.vigicrues.gouv.fr) is the trademark and the front door for flood forecasting in France. On this site, the general public has access to flood vigilance information, flood forecast bulletins and real time water level and discharge data at significant points. The water levels (or discharges) reached during a few historical events are also displayed. Vigicrues is still under development with the forthcoming display of forecast plots and forecasted flooded areas. All these information will be soon completed with high-water marks data, bringing local references to be compared with current water levels or flood forecasts.

\footnotetext{
${ }^{18} \mathrm{BDHI}$ (Base de Données Historiques sur les Inondations) is a database about historical flood events in France
}

Banque hydro (www.hydro.eaufrance.fr) is the national repository for hydrometric data, which has been gathering validated water level and discharge data from all kind of hydrometric services (public services or private companies) for decades. The national high-water marks repository is aimed to be the Banque Hydro's equivalent for localized high-water levels.

Apart from these institutional sources, there are also a lot of other databases or websites (run by local authorities, river basin districts etc.) that can opportunely be related to the national high-water marks repository.

To avoid redundancy and update issues, strong links between these websites and databases are intended; our site's web services will of course be particularly useful.

\section{Conclusion}

In the purpose of sharing and standardization of highwater marks data collection, storage and management, the previously presented work leans on two mainstays: the first one dealing with field investigations, the second one dealing with data storage, management but also broadcasting towards the general public. Tools have been developed for on-field work as for office tasks, with the aim of meeting most of the identified needs. Yet, the main issue of the approach seems to be concerning stakeholders organization. Beyond the technical aspects, only an appropriate distribution of the roles can make this integrated approach successful.

The launch of the platform is planned during 2016, in two steps: first, opening to institutional contributors only (mainly governmental services and river basin districts); and then, opening to the general public, which stands for the official and visible outcome of the project. The success of the whole approach will probably be assessed during the next flood events, especially concerning the general public involvement and the correct function of the complete chain.

\section{References}

1. Gazelle F., Maronna K. (2009). Conservation et disparition des repères de crues - Exemple des repères apposés après la crue de 1930 en Lot-etGaronne et dans le sud du Tarn, Physio-Géo, Vol. 3/2009, p. 21-33. https://physio-geo.revues.org/645

2. Cerema (2016). Protocole de collecte d'informations par reconnaissances de terrain suite à une inondation. Guide méthodologique.

3. Etablissement public territorial du bassin de la Dordogne (2010). Etude de retour d'expérience de trois épisodes orageux de juin 2007 et mai 2008 sur le bassin de la Dordogne, rapport d'étude. 
4. DDE de l'Essonne (2007). Recensement des zones inondées suite à l'orage du 29 avril 2007 sur les communes de Villiers-le-Bâcle et Gif-sur-Yvette.

5. Ministère de l'aménagement du territoire et de l'environnement, BRL Ingénierie (2001). Etablissement de modèles de cahiers des charges en vue d'établir les caractéristiques d'une inondation. Volume 1 : Analyse des pratiques usuelles, Volume 2 : Guide pratique et modèle de cahier des charges.

6. Direction régionale de l'environnement MidiPyrénées, Maronna K., Gazelle F. (2005). Document méthodologique pour le recueil d'informations relatif à une inondation.

7. USGS (2016). Identifying and preserving high-water mark data, Techniques and Methods 3-A24. http://pubs.usgs.gov/tm/03/a24/tm3a24.pdf

8. Maronna K., Gazelle F. (2001). Album des photographies de repères de crues dans le basin du Tarn. Rapport à la DIREN Midi-Pyrénées. 